\title{
EXISTE ESPAÇO PARA O ENSINO DE EDUCAÇÃO FÍSICA NA ESCOLA BÁSICA?
}

\author{
Marcus Aurélio Taborda de Oliveira*
}

\section{RESUMO}

Esse trabalho objetiva apontar algumas perspectivas para o redimensionamento da Educação Física no interior da instituição escolar. Procura evidenciar a falta de horizontes para o atual modelo adotado na escola. Por outro lado, aponta algumas possibilidades de reversão de um quadro pouco promissor, quando imputa à Educação Física a organização, a sistematização e a decodificação das práticas corporais de homens e mulheres, para além dos limites cinestésicos. Tem na corporalidade sua possibilidade de compreensão e explicitação da dinâmica cultural e defende o professor de Educação Física como o intelectual responsável por essa tarefa no plano das práticas corporais. PALAVRAS-CHAVE: Educação Física escolar; formação profissional; políticas públicas para a Educação Física escolar.

O pensamento só pode enfrentar a tarefa de transformar o mundo se não se esquivar à luta pela autotransformação, ao acerto de contas com aquilo que ele tem sido e precisa deixar de ser.

LEANDRO KONDER

Certamente, por muito tempo, intelectuais e pesquisadores da área da Educação Física ${ }^{1}$ desconsideraram a questão proposta por esse trabalho. Em muitos casos por estarem convencidos de que a Educação

* Professor de Metodologia e Prática de Ensino de Educação Física, do Departamento de Teoria e Prática de Ensino, do Setor de Educação, da Universidade Federal do Paraná. Doutorado em Educação: História, Política, Sociedade, na PUC/SP.

Pensar a Prática 2: 119-135, Jun./Jun. 1998/1999 
Física tem um espaço garantido diante do conjunto das atividades pedagógicas. Sem sombra de dúvida, enquadra-se nesse caso o tom apologético impresso pela psicomotricidade (Le Boulch, 1983; Lapierre \& Aucouturier, 1986). Em outros casos, por estarem ainda banhados pelas orientações clássicas do pensamento pedagógico brasileiro que, desde o pensamento jesuítico, reserva um espaço para as atividades físicas nos currículos escolares (Azevedo, 1961, 1996). Mas, o que se vê hoje é a história desalojando a Educação Física do espaço escolar. Que instrumentos posso utilizar para fazer essas afirmações? E, pergunto, que possibilidades temos nós, professores de Educação Física, de reverter esse quadro? ${ }^{2}$

No cerne das discussões desenvolvidas nos últimos anos acerca da legalidade ou da legitimidade da Educação Física escolar, há de se considerar que seus pesquisadores pouco se preocuparam em redimensionar sua prática dentro da escola a partir de um novo foco de análise dos conteúdos escolares. Por muito tempo, eu diria que por toda a história da Educação Física no Brasil - com exceção, talvez, de Inezil Pena Marinho quando faz referências ao folclore e a uma perspectiva hedonista das práticas corporais reportando-se a Herbert Marcuse - houve a preocupação em consolidar os mesmos conteúdos clássicos (Soares et al., 1992) em todos os momentos de seu desenvolvimento histórico.

Considerando que o ideário de uma determinada época conforma a produção humana daquele período, há de se questionar por que a Educação Física sempre se limitou a apenas adaptar-se às orientações dadas, ou por outras áreas do conhecimento, ou pelas políticas públicas e seus desdobramentos. E aqueles que defendiam sua importância nos currículos escolares freqüentemente se mostravam tão despreparados para essa empreita quanto aqueles que defendiam sua total irrelevância. ${ }^{3}$

Desde a sua chegada à escola brasileira no final do século passado, a Educação Física tem sido "defendida" ou "atacada" por intelectuais de outras áreas. Talvez se possa alegar a falta de um corpo de intelectuais orgânicos para a área, diferentemente dos quadros da educação que, desde o advento da República, se mostram organizados em grupos cada vez mais influentes. Parece-me que essa alegação é procedente, se levarmos em consideração que a pesquisa em Educação Física no Brasil se desenvolveu somente a partir da década de 70. Também, parece-me razoável considerar que a Educação Física carece, ainda hoje, no seu 
sentido amplo, de uma maior definição epistemológica, conforme nos aponta Bracht (1995). Mas, tanto um quanto outro, são problemas a serem discutidos em outros espaços, por não serem o objeto específico deste trabalho.

Trabalhos como os de Castellani Filho (1988), Soares (1993) e Carvalho (1995) demonstram algumas das formas pelas quais se foi delineando o pensamento da Educação Física no Brasil. Todos eles trazem como orientação comum a vinculação ideológica da área a fatores exógenos. ${ }^{4}$ Assim, o que se viu historicamente foi um conjunto de práticas físicas sendo institucionalizadas sem um corpo próprio de conhecimentos que justificasse sua legitimação. Essa constatação se faz importante, pois é um dos elementos que me permitem afirmar que a Educação Física escolar deve passar por uma renovação absolutamente total se quiser ter fôlego para se manter nos currículos escolares.

$\mathrm{O}$ descaso dos profissionais e pesquisadores da área com as mudanças impressas no comportamento através da história, mormente a partir da primeira década que se seguiu à $2^{\mathrm{a}}$ Grande Guerra, ${ }^{5}$ mudanças manifestas fundamentalmente nas práticas e códigos corporais da sociedade, mantiveram a Educação Física numa condição de atividade catártica no interior da escola. $\mathrm{O}$ senso comum nos traz claramente essa visão quando nos aponta a Educação Física como muito importante para o dispêndio de energia. Mas, o profissional de Educação Física pouco avança nesse sentido (Daólio, 1995). Analisando dados coletados em trabalhos desenvolvidos durante os quatro últimos anos passados, percebi claramente que:

1) o profissional de Educação Física que atua na escola não tem clareza de seu papel junto à instituição escolar, confundindo-a freqüentemente com o clube, com a academia, com a escolinha desportiva etc. Se desconsiderarmos sua necessidade de sobrevivência, a maior parte desses profissionais não atuaria na escola. A educação escolar ainda representa o maior campo de trabalho para esse profissional por uma questão única e exclusiva de demanda profissional (mercado de trabalho). Refiro-me, certamente, à realidade de Curitiba e, muito provavelmente, do Estado do Paraná. Não disponho de dados para afirmar o mesmo com relação a outras regiões.

2) um grande número de respostas coletadas junto aos professores de Educação Física da rede pública municipal de Curitiba aponta alguPensar a Prática 2: 119-135, Jun./Jun. 1998/1999 
mas lacunas graves na formação e representação desse mesmo profissional. Em linhas gerais ele considera a escola um lugar "difícil de trabalhar" porque "são muitos alunos", de "idades diferenciadas", "sem interesse pela Educação Física", "sem condições de trabalho" além de o profissional dispor de um "salário muito baixo".

Ora, o que o professor está chamando de "difícil", em primeiro lugar são as próprias condições da escola pública, hoje. Em segundo lugar, esse profissional desconsidera completamente o elemento humano, no sentido de sua totalidade ${ }^{6}$ e subjetividade, em suas análises. Sem dúvida, predomina ainda em nossas escolas uma abordagem naturalista de Educação Física, acrítica e aistórica que, não raramente, reduz o homem à condição de ser natural, apenas biológico, negando a Educação Física como uma prática social e essa como determinação ideológica. Afora as claras dificuldades na formação profissional que, por questões óbvias, não serão discutidas aqui nesse espaço, um dos grandes problemas, sem dúvida, está na percepção dos profissionais de Educação Física na importância da sua própria prática, o que me remete à problemática da competência deste profissional. Isso porque, para se trabalhar com a corporalidade $^{7}$ do educando, é preciso que deixemos para trás, no interior da escola, uma compreensão de Educação Física baseada na premissa do movimento como inerente à condição humana, a comunidade humana como algo homogêneo, e as práticas corporais restritas ao âmbito da motricidade.

Nesse sentido, uma análise da nova Lei de Diretrizes e Bases da Educação Nacional demonstra o espaço reservado hoje para a Educação Física nos currículos básicos: nenhum! A ambigüidade da nova lei não garante qualquer possibilidade de permanência da Educação Física nos currículos da escola básica. Por outro lado, em dois de seus eixos principais estabelece a inclusão do ensino da Ética e da Educação Sexual no currículo escolar. No caso da ética, a justificativa do MEC é a falta de padrões comportamentais de referência para juventude, manifesta, principalmente, no crescimento da violência entre crianças, adolescentes e jovens. Já, no caso da educação sexual, justifica-se pelo alarmante número de mães adolescentes, a partir dos doze anos (Brasil, 1996). Sem entrar no mérito da iniciativa do ministério, o que eu gostaria de chamar a atenção é justamente para a contradição dos elementos expostos anteriormente: a institucionalização do ensino de elementos importantís-

OLIVEIRA, M. D. T. Existe espaço para o ensino de educacação física ... 
simos na formação do homem na escola básica, uma vez que essas dimensões humanas não eram desenvolvidas, a não ser de uma maneira pouco profícua (a sexualidade discutida do ponto de vista da biologia e a ética do ponto de vista dos estudos sociais); e a não-contemplação no texto da lei da manutenção de uma disciplina que tem como elemento fundamental de análise as manifestações corporais, que é a Educação Física. ${ }^{8}$ Ocorre-me uma questão: por que a Educação Física na escola nunca se preocupou em abordar - como área responsável pela sistematização crítica e competente dos elementos da cultura corporal, pelas práticas e manifestações corporais dos sujeitos na sociedade - a sexualidade e a violência, por exemplo, uma vez que ambas se manifestam no corpo e podem exprimir uma linguagem, uma determinada condição de classe, seja do ponto de vista do poder ou da condição material dos sujeitos sociais? Ouso afirmar que, como aliás ocorre com certa freqüência, os intelectuais do Estado se anteciparam aos intelectuais da área da Educação Física e ajustaram os currículos escolares às novas exigências da cultura. Só que, nesse caso específico, "tratorando" um componente curricular que há muito não sabe a que veio. No meu entendimento, porém, a Educação Física aparece como única atividade dos currículos escolares hodiernos que permite uma abordagem biológica, antropológica, sociológica, psicológica, filosófica e política das práticas corporais como manifestação humana, justamente pela sua constituição multidisciplinar.

Considerando que a Educação Física tem como pressuposto básico o desenvolvimento do homem omnilateral a partir da intervenção sobre as práticas corporais dos sujeitos, é função precípua da escola, nessa perspectiva, a abordagem das manifestações corporais de homens e mulheres em sua totalidade, e não apenas na sua dimensão cinética, motora ou biomecânica. A intencionalidade e a significação do movimento humano no plano da cultura o diferenciam fundamentalmente do movimento dos demais seres. Essa qualidade que tem o corpo do homem de comunicar-se e relacionar-se se define em relação a um corpo material, determinado por um mundo material, numa perspectiva histórica. Não se podem negligenciar, portanto, as determinações ideológicas da formação da consciência a partir das orientações impressas por uma sociedade de conflito (Bakhtin, 1995). 
Somente o homem é capaz de produzir cultura e a Educação Física só existe como construção humana e não como um a priori natural. Todos os conteúdos, clássicos ou não, da Educação Física têm sua conformação no jogo cultural. As novas práticas emergentes ${ }^{9}$ são respostas da própria cultura à saturação dos modelos ou práticas passadas, o que implica claramente a necessidade de compreensão da dinâmica histórica e cultural das práticas corporais (Kolyniak Filho, 1996). Walter Benjamin, citado por Konder (1988), destacou que "em cada época, é preciso arrancar a tradição ao conformismo, que está sempre procurando dominá-la" (p. 92). Talvez hoje, a partir das dificuldades de manutenção dos padrões clássicos de Educação Física na escola, possamos sair de um estado de letargia profunda e começar a procurar novos referenciais para a Educação Física no interior da escola. Acredito que a Educação Física muito em breve "deverá ser" a disciplina escolar capaz de aglutinar em torno dela a totalidade e a complexidade das manifestações corporais dos sujeitos no plano da cultura.

Em nossos currículos escolares "quem" ou "o quê" aborda as questões referentes aos preconceitos raciais, às divergências étnicas, aos conflitos de classe manifestos no corpo, às relações de gênero e à definição dos papéis sexuais no contexto societário, à violência, à sexualidade, ao consumo de drogas? Não são essas questões prementes no modelo de sociedade que desenvolvemos? Não são questões a que estão expostos os sujeitos em nossa cultura, principalmente nossos educandos? Não são questões que conformam novas formas de relação e convívio social? Não são relações que se manifestam explicitamente através de práticas corporais? ${ }^{10}$ Se a resposta para essas questões for "sim", creio que a escola tem um papel fundamental na sua condução e, dentro da escola, a Educação Física é a disciplina, por excelência, para sua abordagem. Se a resposta for "não", acredito que a Educação Física tende ao desaparecimento nos currículos escolares. Isso porque são claras as referências a uma saturação por parte dos educandos do tradicional modelo esportivo, hegemônico ainda hoje no interior da escola, ainda que com nuanças mais suaves. ${ }^{11}$

Assim, é fundamental que pesquisadores, intelectuais e profissionais da Educação Física que tenham a Educação Física escolar como um dos seus objetos de estudo ou de trabalho compreendam primeiro que a escola se estrutura de acordo com os valores prevalecentes de uma 
determinada organização social, mas pode atuar numa perspectiva de crítica e superação desses mesmos valores. Dialeticamente a escola determina novos padrões de comportamento, ao mesmo tempo que é determinada pelo conjunto de tencionamentos de uma sociedade marcada pela exclusão, pela divisão social e pelo conflito. Segundo: um semnúmero de práticas corporais surge e desaparece, algumas por conta dos modismos de toda ordem, outras por incapacidade da própria escola de sistematizá-las; muitas dessas práticas são incorporadas por outras áreas do conhecimento ou se transformam em áreas próprias, diferenciadas da Educação Física. E isso tudo sem que a Educação Física tenha sequer se proposto a discuti-las!

É mister que os profissionais da Educação Física a redimensionem, então, na direção de compreender as práticas corporais num plano mais amplo, como já foi apontado aqui. Acredito que, para isso, seus profissionais deverão enfrentar os seguintes desafios:

1) superar seu caráter de mera atividade, de "prática pela prática";

2) buscar sua legitimidade no contexto escolar;

3) integrar-se ao processo pedagógico como um dos elementos fundamentais do desenvolvimento do educando sem, contudo, usar de sua especificidade para auto-exilar-se no interior da escola;

4) diferenciar-se de uma perspectiva "tarefeira", espontaneísta, voluntariosa;

5) assumir-se como profissionail de uma área do conhecimento que tem um saber a ser desenvolvido no meio escolar;

6) ampliar seu campo de intervenção para além das abordagens centradas na motricidade;

7) compreender as práticas corporais, pedagógicas e a própria organização social como constructos culturais;

8) eleger o homem como fim último das práticas corporais, invertendo a ordem hegemônica que considera o movimento humano como algo que subsiste por si, independente de sua humanização.

Os estudos em biomecânica, em aprendizagem motora, em biologia do exercício e em outras áreas devem servir de suporte científico para o desenvolvimento das práticas corporais, tanto quanto os estudos filosóficos, sociológicos, antropológicos, históricos, uma vez Pensar a Prática 2: 119-135, Jun./Jun. 1998/1999 
que estes também são manifestações expressas da cultura. Por outro lado, não se pode mais confundir o profissional da Educação Física escolar com o técnico desportivo, com o recreacionista ou com o organizador de festas, gincanas, colônias de férias; assim como não se pode continuar confundindo Educação Física com aprendizagem motora, biomecânica, esporte, recreação etc. (USP, 1996). As práticas corporais não podem continuar sendo entendidas apenas como manifestação cinestésica, uma vez que trazem em si a conformação dos signos sociais, sua representação e transmissão. E o profissional de Educação Física precisa compreender-se como aquele intelectual responsável pela organização e sistematização competente e pela crítica das práticas corporais conscientes do homem e suas determinações pelas relações com o trabalho, com a linguagem e com o poder, elementos estruturantes de uma sociedade cindida em classes e, conseqüentemente, em interesses antagônicos. O trabalho, no sentido de transformação da condição natural do homem, produzindo, este, a sua história própria. Porém, essa produção da história (cultura) não se dá sem um substrato ideológico que determina as formas de linguagem. A conformação dos signos sociais (palavra, gesto etc) se dá sempre num contexto de relações sociais e orientações ideológicas (Bakhtin, 1995). Finalmente, as relações de poder, também orientadas pelo jogo de forças determinado ideologicamente pela própria cultura, que cristaliza a condição dos sujeitos em determinada estrutura social. Pensar a Educação Física no interior da escola sem pensar os seus determinantes culturais é, como a sua história bem tem demonstrado, torná-la acéfala.

À guisa de conclusão, é importante destacar alguns elementos que julgo importantes: o primeiro deles é de ordem estrutural. Não se trata de fazer apologia de uma revolução educacional pelos meandros da Educação Física. Além da ingenuidade expressa numa pretensão dessa envergadura, os meus próprios apontamentos indicam a necessidade de uma inserção mais ampla no plano da história e da cultura para se intentar qualquer tipo de mudança significativa, sem os desvarios dos modismos. No caso específico da Educação Física, acredito que, na verdade, a mudança se dará por inércia. Trata-se de uma questão bastante objetiva: "se correr o bicho pega, se ficar...". Mas, mesmo que se dê dessa maneira, é condição sine qua nomque seus pesquisadores e profissionais ${ }^{12}$ compreendam a dinâmica escolar e deixem de imaginar que a

OLIVEIRA, M. D. T. Existe espaço para o ensino de educacação física ... 
Educação Física no interior da escola é diferente do restante da estrutura escolar que, por sua vez, reproduz em micro-escala as relações mais amplas da sociedade (Foucault, 1979). Se não se trata de fazer da Educação Física o carro da história - no que diz respeito à educação escolar -, por outro lado também não se trata de colocá-la numa posição de total subserviência a essa mesma estrutura. Ora, pelos argumentos defendidos aqui, espero ter deixado claro nossa crença na importância da Educação Física na formação, desde que se preocupe com o mesmo sujeito como uma construção histórica, social e cultural. Nesse sentido, a motricidade assume um papel complementar na formação humana e não, seu fim último. Acredito que, propiciando no meio escolar a abordagem da corporalidade da maneira como aqui foi explicitada, a Educação Física tem muito a contribuir no sentido da organização da própria escola e da formação do educando, uma vez que, acredito também, essa abordagem potencialize a dimensão crítica das relações e práticas corporais.

O segundo elemento é de ordem profissional: o profissional de Educação Física não pode continuar se apresentando como um organizador de torneios e festas perante a sociedade. É necessário que ele se apresente como um gerador, um difusor, um crítico de idéias. Idéias sobre a corporalidade, a organização social e política da sociedade, sobre a cultura. Ainda que o categoria do professor, de maneira geral, esteja desvalorizada, dificilmente a sociedade abriria mão da escola, bem como, não abriria mão do ensino "clássico" da língua, da matemática ou da ciência. Essa discussão nos remete novamente à questão da legitimidade, que só pode se dar por inferência política (Bracht, 1992). No caso da Educação Física e seus profissionais, não raramente ele é apresentado como um sujeito pouco comprometido com a escola, inconseqüente, sem uma função específica dentro da própria instituição, não fosse pela organização de "peladas". ${ }^{13}$ Certamente contribui para isso o que foi apontado por Daólio (1995), quanto à distância existente entre o professor que efetivamente se encontra no dia-a-dia da escola e a produção acadêmica da área. O profissional que desenvolve cotidianamente seu trabalho junto à comunidade tem dificuldade de acesso à produção acadêmica, inclusive pela distância que a universidade e os centros de pesquisa mantêm desses profissionais. O papel do professor de Educação Física deve ser inequívoco na organização da escola. Isso me remete Pensar a Prática 2: 119-135, Jun./Jun. 1998/1999 
novamente ao aspecto fundamental da relação entre competência e compromisso (Mello, 1988; Carmo, 1982; Oliveira, 1996). Não pode ser confundido com devaneios corporativistas que procuram apenas $\mathrm{o}$ resguardo de interesses discutíveis. ${ }^{14}$

Portanto, destacados esses dois pontos, afirmo que a Educação Física tem um papel fundamental no quadro da organização da cultura, desde que se disponha a compreendê-la em toda a sua amplitude. A partir das práticas corporais, da sua organização, da sistematização e da decodificação, existe um espaço pouco e mal explorado dentro da instituição escolar. Esse é o espaço de uma nova maneira de compreender as manifestações corporais como expressão inequívoca da cultura.

Por fim, o que proponho é que, mantidos os conteúdos clássicos da Educação Física e contemplados os seus conteúdos emergentes, ambos expressão objetivada da consciência histórica, frutos da própria dinâmica da produção cultural, os programas escolares de Educação Física sejam desenvolvidos a partir da corporalidade do homem na sua dimensão mais ampla, já apontada nesse trabalho. Esse intento representa, indubitavelmente, uma mudança de categoria axiológica. ${ }^{15}$ Exige que o profissional de Educação Física pense o mundo, o homem e a organização social a partir de uma nova perspectiva mais ampla, menos fragmentada. Essa perspectiva supera a visão do homem-motor e pensa o homem a partir da sua construção histórico-cultural. Seu objetivo primeiro deve ser a busca da mudança/transformação dos padrões de relação dos homens entre si e com a natureza. Para isso, é preciso considerar a pluralidade da condição humana, na tentativa de possibilitar a todos os homens e mulheres sua humanização plena. Assim, no plano mais amplo, para além de suas especificidades técnicas, o professor de Educação Física precisa tornar-se um profissional pensador da cultura. Deve compreender a singularidade dos sujeitos no contexto da época em que vivemos para, a partir de sua determinações históricas, projetar seu futuro. Isso representa integrar-se a uma visão de mundo baseada no encontro dialógico com o outro, dentro de uma dimensão ética. Todas as minorias (de sexo, cor, raça, condição social) e a sua condição de sujeitos no mundo são seus objetos de análise e compreensão da realidade, a partir dos seus códigos corporais próprios (Marcuse, s.d). Isso, para poder compreender a dinâmica da produção cultural diante da dominação característica de uma sociedade de classes. Não é possível produzir 
o universal sem a particularidade/singularidade da produção de indivíduos, uma vez que isso não representa a capitulação da visão de totalidade. Porque a totalidade está encarnada justamente na possibilidade histórica contraditória da produção cultural, o que imputa aos sujeitos individuais, no contexto societário, necessariamente uma tomada de posição perante o mundo. E isso não se dá passivamente por adição de experiências motoras ou não -, mas, a partir da crítica, do embate, do conflito e da contínua superação da provisoriedade do conhecimento historicamente produzido (Gramsci, 1985). Sem sombra de dúvida esse é o espaço da Educação Física na escola, da educação infantil ao ensino médio.

\section{ABSTRACT}

This work has the objective to show some perspectives for a new dimension of Physical Education inside school instituition. Also try to put in evidence the absence of new horizons for the present model in use at school. On the other side, it points out some possibilities to revert this situation not too much promising, when it impute to Physical Education the organization, systematization, and decodefication of men and women corporal practices, beyond cinestesic limits. There is in the corporability its own possibility of comprehension and explicity of cultural dynamics, considering Physical Education teacher as the intelectual responsible for this work as far as corporal practices are concerned.

KEY WORDS: physical education; professional training in physical education; public politics in physical education.

\section{NOTAS}

1. Educação Física entendida aqui como o conjunto de práticas corporais desenvolvidas e transformadas por homens e mulheres no contexto sócio-cultural. Nos limites deste trabalho estarei reportando-me ao termo Educação Física no sentido estrito proposto por Bracht (1992), que se refere especificamente ao espaço circunscrito da instituição escolar.

2. Cabe destacar que as idéias discutidas nesse trabalho são fruto de diferentes tipos de intervenção desenvolvidas nos quatro últimos anos: num primeiro caso, os cursos de aperfeiçoamento oferecidos pelo Estado do Paraná e pela Prefeitura de Curitiba aos professores das duas redes de ensino; depois, os contatos permanentes travados 
com a rede pública através da disciplina de Prática de Ensino e Estágio Supervisionado de Educação Física do Curso de Licenciatura em Educação Física da Universidade Federal do Paraná; e, finalmente, um projeto de pesquisa, infelizmente não levado a cabo, junto aos professores da rede pública municipal de Curitiba.

3. Nesse sentido vale destacar Fernando de Azevedo e suas obras clássicas Da Educação Física (1931) e A cultura brasileira (1996), dentre outras, como um dos intelectuais que se enquadram no primeiro caso aqui apontado.

4. Castellani (1988) demonstra a vinculação da Educação Física com a ideologia de Estado, principalmente durante o Estado Novo; Soares (1993) estabelece conexões entre a implantação da Educação Física no Brasil e sua vinculação ao ideário médico-higienista europeu; por fim, Carvalho (1995) apresenta a relação mitificadora entre atividade física e saúde, e o uso ideológico que se pode fazer dessa relação.

5. O pós-guerra representa, após o primeiro momento de reconstrução, principalmente da Europa, um período de alguma estabilidade no plano das relações entre as nações mas, de um grande influxo de idéias revolucionárias no plano da cultura e da relação entre as gerações. A "Idade da Ciência" da qual nos fala Granger (1994) favorece a comunicação de massa, o aparecimento da pílula anticoncepcional e as experiências com drogas naturais ou sintéticas. Por outro lado, a ruptura com os valores da família nuclear tradicional burguesa remete toda uma geração aos postulados de um semnúmero de intelectuais das mais diferentes perspectivas, capitaneados pelos ensinamentos filosóficos de Herbert Marcuse (1978) para o plano da cultura. Novas formas de comunicação planetária e novas formas de comportamento acabam por alterar drasticamente muitas das maneiras de se pensar, sentir e usar o corpo. Os rescaldos desse período histórico ainda ressoam principalmente no plano cultural, o qual determina os padrões de prática corporal de uma determinada sociedade.

6. Para Kosik (1995, p. 44), "Totalidade significa: realidade como um todo estruturado, dialético, no qual ou do qual um fato qualquer (classe de fatos, conjuntos de fatos) pode vir a ser racionalmente compreendido". E continua, diferenciando a compreensão de totalidade dialético-materialista das concepções positivista e estruturalis- 
ta: "A totalidade concreta como concepção dialético-materialista do conhecimento do real significa, portanto, um processo indivisível, cujos momentos são: a destruição da pseudoconcreticidade, isto é, da fetichista e aparente objetividade do fenômeno, e o conhecimento do caráter histórico do fenômeno, no qual se manifesta de modo característico a dialética do individual e do humano em geral; e, enfim, o conhecimento do conteúdo objetivo e do significado do fenômeno, da sua função objetiva e do lugar histórico que ele ocupa no seio do corpo social" (p. 61).

7. Ao conjunto de práticas corporais do homem, sua expressão criativa, seu reconhecimento consciente e sua possibilidade de comunicação e interação na busca da humanização das relações dos homens entre si e com a natureza estou chamando de corporalidade. A corporalidade se consubstancia na prática social a partir das relações de linguagem, poder e trabalho, estruturantes da sociedade. No caso específico deste trabalho, a sociedade capitalista contemporânea.

8. O art. 26 da Lei de Diretrizes e Bases da Educação Nacional, em seu parágrafo $3^{\circ}$, estabelece que "a educação física, integrada à proposta pedagógica da escola, é componente curricular da Educação Básica, ajustando-se às faixas etárias e às condições da população escolar, sendo facultativa nos cursos noturnos" (O grifo é meu). Já, no seu art. 27, IV, estabelece como diretriz a "promoção do desporto educacional e apoio às práticas desportivas não formais" (O grifo é meu). Aqui ocorrem três questões preocupantes do ponto de vista da Educação Física escolar: a) a Educação Física é um componente curricular, mas a lei não aponta como deverá se organizar; b) alija a população da escola noturna da Educação Física, embora esse fator mereça um maior aprofundamento (no caso específico do Estado do Paraná, o ensino de Educação Física no turno da noite já não existe mais, desde 1998, num claro aproveitamento por parte da Secretaria do Estado da Educação das "brechas" do texto legal); c) aponta o desporto educacional como diretriz, o que tem sido profundamente questionado em função da limitação de sua intervenção. Se a questão legalidade versus legitimidade é importante, não é menos importante considerar o retrocesso que significa perder espaço legal. Porém, é a partir desse nova situação criada que a Educação Física poderá ser redefinida ou estará indelevelmente condenada ao desapareci- 
mento na escola. Quanto à questão do esporte educacional tive a oportunidade de apresentar um trabalho no Congresso Latino-americano de Esporte para Todos, Esporte-educação: o discurso falacioso, em que procurei demonstrar o completo equívoco dessa denominação. (Oliveira, 1996)

9. Estou denominando práticas emergentes um conjunto de atividades corporais (desportivas, recreativas etc) que cada vez mais tem sido utilizadas no interior das escolas como atividades curriculares. Como exemplo cito a escalada em paredes, os acantonamentos/acampamentos, os esportes radicais, dentre outros. Pierre Palerbas tem atentado para essas práticas com alguma insistência (Anais do I Congresso Latino-americano de Esporte para Todos. Santos, 1996).

10. Por práticas corporais estou compreendendo toda a dimensão comunicativa do movimento humano, desde os gestos mais simples e elementares até as formas mais complexas de treino corporal. Nesse particular cabe destacar que o conceito de corporalidade não pode, pela sua própria amplitude, desconsiderar como prática corporal nossos atos mais mecânicos, cotidianos, como escrever, andar, sentar e outros. Esses atos também exprimem uma forma de comunicar-se e relacionar-se com o mundo. Não são, contudo, elementos a serem sistematizados pela escola, uma vez que são automaticamente transmitidos pelos próprios códigos de conduta de uma determinada conformação social. Não se pode falar o mesmo das outras dimensões corporais apontadas nesse trabalho, uma vez que não são abordadas pela escola, mas são pelo conjunto social (senso comum), sob um ponto de vista parcial, fragmentado, preconceituoso, estereotipado.

11. Tanto as experiências com a disciplina de Prática de Ensino e Estágio Supervisionado de Educação Física quanto as respostas dos professores da rede pública permitem-me concluir por essa saturação. Os alunos têm solicitado atividades diferenciadas de seus professores que, por questões óbvias de formação e falta de atualização, têm tido dificuldades em responder a esse desafio. Um outro exemplo significativo é a busca de alguns dos principais grupos de escolas particulares, aquelas que, notadamente, por muito tempo serviram de referência desportiva, inclusive para as escolas públicas, 
estarem buscando alternativas para o ensino da Educação Física no $1^{\circ}$ e no $2^{\circ}$ graus, uma vez que suas "clientelas" não respondem mais aos apelos do esporte com o mesmo entusiasmo.

12. Em algumas passagens desse texto uso os termos profissional, professor, pesquisador ou intelectual. Cabe esclarecer que, em termos amplos, considero as quatro denominações como intelectuais no sentido proposto por Gramsci (1985), para quem toda atividade humana pressupõe uma atividade intelectual. A distinção às vezes aparece para diferenciar aqueles que efetivamente desenvolvem programas de Educação Física na escola daqueles que têm como função própria "pensar" sobre esse trabalho, no sentido da produção de um saber acadêmico.

13. Nesse particular é especialmente ilustrativa a grande dificuldade de campos de estágio para nossos acadêmicos de $3^{\circ}$ e $4^{\circ}$ ano. Temos tido como retorno das escolas duas situações típicas: numa delas, diretores, supervisores e afins negam o estágio com o argumento trágico para a Educação Física - que, para jogar bola, os alunos se organizam sozinhos. A outra situação fica bem caracterizada na negativa de um professor de Educação Física de uma escola estadual com o argumento que os estagiários "iriam dar aulas". Nesse caso, "os alunos da escola depois vão ficar querendo que eu dê aulas também, e minha situação fica chata, complicada".

14. Estou referindo-me à recente regulamentação da profissão de professor de Educação Física, de corte essencialmente corporativo que, no meu entendimento, carece de justificativas consistentes para legitimar-se.

15. Para Silva (1988) "categoria axiológica refere-se ao valor enquanto algo significativo, necessariamente presente à vida humana ao mesmo tempo determinante e determinado pelo processo humano de existir". O termo é usado pela autora como sinônimo de "categoriavalor" e "valor".

\section{REFERÊNCIAS BIBLIOGRÁFICAS}

AZEVEDO, Fernando. Da Educação Física: o que ela é, o que tem sido e o que deveria ser. 5. ed. São Paulo: Melhoramentos, 1961. 
. A cultura brasileira. Brasília: Ed. UnB, Rio de Janeiro: Ed.

UFRJ, 1996.

BAKHTIN, Mikhail. Marxismo e filosofia da linguagem. São Paulo: Hucitec, 1995.

BRACHT, Valter. Educação Física e aprendizagem social. Porto Alegre: Magister, 1992.

. As ciências do esporte no Brasil: uma avaliação crítica. In: NETO, Amarílio Ferreira et al. As ciências do esporte no Brasil. Campinas: Autores Associados, 1995.

BRASIL. Congresso Nacional. Lei $n^{\circ}$ 9.394/96 (Diretrizes e Bases da Educação Nacional).

CARMO, Apolônio Abadio. Educação Física: crítica de uma formação acrítica. Um estudo das habilidades e capacidades intelectuais solicitadas na formação do professor de Educação Física. São Carlos, 1982. Dissertação (Mestrado) - Universidade Federal de São Carlos.

CARVALHO, Yara Maria. O “mito” da atividade física e saúde. São Paulo: Hucitec, 1995.

CASTELLANI FILHO, Lino. Educação Física no Brasil: a história que não se conta. Campinas: Papirus, 1988.

DAÓLIO, Jocimar. Da cultura do corpo. Campinas: Papirus, 1995.

FOUCAULT, Michel. Microfísica do poder. Rio de Janeiro: Graal, 1979.

GRAMSCI, Antonio. Os intelectuais e a organização da cultura. Rio de Janeiro: Civilização Brasileira, 1985.

GRANGER, Gilles-Gaston. A ciência e as ciências. São Paulo: Ed. UNESP, 1994.

KOLYNIAK FILHO, Carol. O objeto de estudo da educação física em discussão: um diálogo com Manuel Sérgio. Discorpo. (São Paulo), v. 6, p. 79-92, jan./jun. 1996.

KONDER, Leandro. Walter Benjamin: o marxismo da melancolia. Rio de Janeiro: Campus, 1988.

KOSIK, Karel. Dialética do concreto. Rio de Janeiro: Paz e Terra, 1995. MARCUSE, Herbert. Eros e civilização. Rio de Janeiro: Guanabara, s.d. . Razão e revolução. Rio de Janeiro: Paz e Terra, 1978. 
OLIVEIRA, Marcus Aurelio Taborda. Licenciatura em Educação Física: que curso é esse?. Synopsis. (Curitiba), v. 7, p. 118-129, dez. 1996. . Esporte-educação: o discurso falacioso. In: CONGRESSO LATINO-AMERICANO DE ESPORTE PARA TODOS, 1. Anais... Santos, 1996.

PALERBAS, Pierre. O significado do esporte na sociedade contemporânea. In: CONGRESSO LATINO-AMERICANO DE ESPORTE PARA TODOS, 1. Anais... Santos, 1996.

SILVA, Sônia Aparecida Ignácio. Valores em educação. Petrópolis: Vozes, 1988.

SOARES, Carmem Lúcia, TAFFAREL, Celi Neuza et al. Metodologia do ensino de Educação Física. São Paulo: Cortez, 1992.

SOARES, Carmen Lúcia. Educação Física: raízes européias e Brasil. Campinas: Autores Associados, 1994.

UNIVERSIDADE DE SÃO PAULO. Características e diretrizes dos cursos de Bacharel em Educação Física, Licenciatura em Educação Física e Bacharel em Esporte. Escola de Educação Física, 1996. (mimeo). 